\title{
Nasal continuous positive airway pressure with supplemental oxygen in coexistent sleep apnoea-hypopnoea syndrome and severe chronic obstructive pulmonary disease
}

\author{
G. Sampol*, M.T. Sagalés**, A. Roca*, M.D. de la Calzada**, J.M. Bofill*, F. Morell*
}

Nasal continuous positive airway pressure with supplemental oxygen in coexistent sleep apnoea-hypopnoea syndrome and severe chronic obstructive pulmonary disease. G. Sampol, M.T. Sagalés, A. Roca, M.D. de la Calzada, J.M. Bofill, F. Morell. @ERS Journals Ltd 1996.

ABSTRACT: The objective of our study was to assess the application of nasal continuous positive airway pressure (nCPAP) with supplemental oxygen for correction of upper airway obstructive episodes and hypoxaemia during sleep in stable patients with sleep apnoea-hypopnoea syndrome (SAHS) and severe chronic obstructive pulmonary disease (COPD).

Ten male patients with symptomatic SAHS and severe COPD (forced expiratory volume in one second $<\mathbf{5 0 \%}$ of predicted) were studied for three consecutive nights. Diagnostic polysomnography was performed the first night and repeated with increasing nCPAP levels, with and without supplemental oxygen on the second and third nights, respectively.

Diagnostic polysomnography showed: mean (SD) apnoea-hypopnoea index 41 (22)

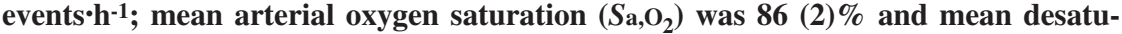
ration nadir was 81 (4)\% during non-rapid eye movement (nREM) sleep and 80 (7)\% and 73 (9)\%, respectively during REM sleep. The application of nCPAP during the second night corrected apnoeas and hypopnoeas, but mean $\mathrm{Sa}_{\mathrm{a}} \mathrm{O}_{2}$ remained $<90 \%$ in all patients. With the addition of oxygen at a flow of $1.5 \mathrm{~L} \cdot \mathrm{min}^{-1}$ at suboptimal nCPAP levels, we observed an increase in apnoea frequency, persistence of apnoeas at nCPAP levels which eliminated them when no supplemental oxygen was administered, and longer duration of apnoeas and hypopnoeas. However, when the effective nCPAP level of the second night was reached with supplemental oxygen during the third night, its efficacy in eliminating apnoeas and hypopnoeas was maintained and, furthermore, all patients presented $\mathrm{Sa}_{\mathrm{a}} \mathrm{O}_{2}>\mathbf{9 0 \%}$, with no greater hypercapnia or cardiac arrhythmias.

We conclude that nasal continuous positive airway pressure with supplemental oxygen constitutes a practical therapeutic alternative for hypoxic patients with sleep apnoea-hypopnoea syndrome and chronic obstructive pulmonary disease. Eur Respir J., 1996, 9, 111-116.
Serveis de *Pneumologia and **Neurofisiologia, Hospital General Universitari Vall d'Hebron, Barcelona, Spain.

Correspondence: G. Sampol Servei de Pneumologia

Hospital General Universitari Vall d'Hebron Passeig Vall d'Hebron 119-129

08035 Barcelona

Spain

Keywords:

Chronic obstructive pulmonary disease sleep apnoea-hypopnoea syndrome sleep hypoxaemia

Received: March 271995

Accepted after revision October 171995

Supported in part by grants from SEPAR and FIS 89/0402, Spain.
Sleep hypoxaemia is one of the main consequences of upper airway collapse in the sleep apnoea-hypopnoea syndrome (SAHS). The coexistence of SAHS and chronic obstructive pulmonary disease (COPD) defines a group of special risk patients since awake and sleeprelated hypoxaemia and hypoxaemic cardiovascular consequences are more marked than those observed in patients with SAHS alone [1-5]. Although the natural history of the SAHS-COPD association is not well-known, a major aim of therapy should be both to correct upper airway obstructive episodes and sleep hypoxaemia. However, the application of nasal continuous positive airway pressure (nCPAP), currently the first-choice therapy for apnoeas and hypopnoeas, might not provide correct arterial haemoglobin oxygen saturation $\left(\mathrm{Sa}_{\mathrm{a}} \mathrm{O}_{2}\right)$ during sleep in patients with severe awake hypoxaemia. Furthermore, nonapnoeic desaturations have been described in these patients after resolution of apnoeas and hypopnoeas [6]. On the other hand, supplemental oxygen, a fully accepted therapy in hypoxaemic COPD patients without SAHS $[7,8]$, corrects nocturnal hypoxaemia but does not eliminate upper airway obstructive episodes and, moreover, may lead to their prolongation and worsening of respiratory acidosis on eliminating the hypoxic drive. Tracheostomy with supplemental oxygen delivered to the tracheal stoma has proved effective in suppression of apnoeas, hypopnoeas and nocturnal hypoxaemia [6].

A more physiological alternative therapeutic approach used in clinical practice for SAHS-COPD patients is the application of combined nCPAP and oxygen, but, to our knowledge, its use has not been specifically evaluated. In addition, upper airway collapse in patients with SAHS 
occurs when the negative pressures produced by diaphragm and chest wall muscle contraction are inadequately opposed by contraction of upper airway muscles [9-11]. Hypoxaemia has been shown to influence this balance of forces and lead to a greater increase in upper airway activity compared with that of the diaphragm [12-14]. We wanted to determine whether the elimination of hypoxaemia by means of nCPAP with supplemental oxygen may, thus, constitute a mechanism favouring upper airway closure and increase the level of nCPAP needed to maintain upper airway patency.

Based on these considerations, we evaluated the effects of the application of nCPAP and nCPAP with supplemental oxygen on apnoeas and hypopnoeas and nocturnal oxygenation in hypoxaemic SAHS-COPD patients.

\section{Methods}

Ten male patients with symptomatic SAHS were recruited from those referred to our hospital for excessive daytime somnolence and severe snoring. All met the criteria for COPD [15], with mean (SD) forced expiratory volume in one second (FEV1) $36(10) \%$ of predicted value, mean FEV1/forced vital capacity (FVC) 47 (10)\% and no appreciable improvement after nebulized bronchodilator (table 1). All subjects were on medical regimens for COPD and none had evidence of acute exacerbation of their lung disease within 8 weeks of the study. None were current smokers.

Patients were studied for three consecutive nights: diagnostic polysomnography (PSG) was performed during the first night; PSG with the application of increasing nCPAP levels during the second night; and PSG with nCPAP was repeated with oxygen applied to the nasal mask during the third night. All subjects gave informed consent to the study, which was approved by the Hospital Research and Ethics Committee.

\section{Techniques}

Lights were turned out each night as close to 11.00 pm as possible and patients were awakened between 6.30 and $7.00 \mathrm{am}$. Airflow was detected by oral and nasal thermistors. Electrocardiagram was recorded from a standard one-lead montage, whilst $\mathrm{Sa}_{2} \mathrm{O}_{2}$ was monitored continuously with a pulse oximeter (Pulsox 7; Minolta, Schaffhausen, Switzerland). Chest wall and abdominal movement was assessed by a respiratory inductive plethysmograph (Respitrace; Ambulatory Monitoring Inc., Ardsley, NY, USA) calibrated nightly prior to recording by the least squares method [18], and its validity was verified at the end of the polysomnography. Data were recorded on a polygraph recorder at a paper speed of 15 $\mathrm{mm} \cdot \mathrm{s}^{-1}$, with the exception of $\mathrm{Sa}_{\mathrm{a}} \mathrm{O}_{2}$ which was recorded on a Hewlett-Packard recorder at a paper speed of 25 $\mathrm{mm} \cdot \mathrm{min}^{-1}$. During the second and third nights, a 20gauge radial catheter (Vygon, Ecoven, France) was inserted to allow arterial blood samples to be drawn.

Application of $n C P A P$. During the second night, recording was started with the application of nCPAP (Sleep Easy II; Respironics Inc., Monroeville, PA, USA) with a pressure of $3 \mathrm{cmH}_{2} \mathrm{O}$, and thereafter mask pressure, monitored with a water manometer connected to a sideport in the mask, was raised approximately every $40 \mathrm{~min}$ until apnoeas and hypopnoeas were abolished or a pressure which the patient would not tolerate was reached. The levels of pressure administered after the starting level of $3 \mathrm{cmH}_{2} \mathrm{O}$ were 5, 7.5, 10, 12.5 and $15 \mathrm{cmH}_{2} \mathrm{O}$.

Application of $n C P A P$ and oxygen. Oxygen was administered through one of the side-ports of the nasal mask with a flow of $1.5 \mathrm{~L} \cdot \mathrm{min}^{-1}$ after verifying that this flow and $3 \mathrm{cmH}_{2} \mathrm{O}$ nCPAP provided an $\mathrm{Sa}_{2} \mathrm{O}_{2}$ of $93-98 \%$ following $30 \mathrm{~min}$ of nasal breathing whilst patients were awake and supine. Recording was started with $3 \mathrm{cmH}_{2} \mathrm{O}$

Table 1. - Individual anthropometric, lung function values, awake and supine blood gases and apnoea-hypopnoea indices for the 10 subjects

\begin{tabular}{|c|c|c|c|c|c|c|c|c|c|c|c|}
\hline $\begin{array}{l}\text { Subj } \\
\text { No. }\end{array}$ & $\begin{array}{l}\text { Age } \\
\text { yrs }\end{array}$ & $\begin{array}{c}\mathrm{BMI} \\
\mathrm{kg} \cdot \mathrm{m}^{-2}\end{array}$ & $\begin{array}{l}\mathrm{FVC} \\
\% \text { pred }\end{array}$ & $\begin{array}{l}\text { FEV1 } \\
\% \text { pred }\end{array}$ & $\begin{array}{l}\text { FEV1* } \\
\% \text { FVC }\end{array}$ & $\begin{array}{l}\text { TLC } \\
\% \text { pred }\end{array}$ & $\begin{array}{c}\mathrm{RV} \\
\% \text { pred }\end{array}$ & $\begin{array}{c}\mathrm{Pa}_{\mathrm{a}, \mathrm{O}_{2}} \\
\mathrm{kPa}\end{array}$ & $\begin{array}{c}{\mathrm{Pa}, \mathrm{CO}_{2}}_{\mathrm{kPa}} \\
\text { - }\end{array}$ & $\begin{array}{c}{\mathrm{Sa}, \mathrm{O}_{2}}_{\%} \\
\%\end{array}$ & $\mathrm{AHI}$ \\
\hline 1 & 65 & 28.8 & 48 & 26 & 39 & 94 & 164 & 8.6 & 5.9 & 92 & 74 \\
\hline 2 & 56 & 30.0 & 53 & 33 & 46 & 115 & 251 & 8.7 & 6.1 & 93 & 15 \\
\hline 3 & 49 & 29.6 & 55 & 39 & 54 & 98 & 188 & 7.8 & 5.8 & 90 & 66 \\
\hline 4 & 61 & 27.3 & 71 & 48 & 50 & 89 & 132 & 8.3 & 4.7 & 91 & 28 \\
\hline 5 & 53 & 38.3 & 58 & 44 & 57 & 114 & 289 & 8.1 & 5.9 & 91 & 63 \\
\hline 6 & 54 & 39.3 & 62 & 47 & 57 & 86 & 166 & 7.8 & 6.4 & 90 & 57 \\
\hline 7 & 67 & 27.4 & 43 & 24 & 39 & 88 & 165 & 8.6 & 5.3 & 93 & 20 \\
\hline 8 & 47 & 30.8 & 60 & 23 & 29 & 127 & 249 & 7.7 & 4.8 & 90 & 22 \\
\hline 9 & 66 & 23.0 & 54 & 43 & 57 & 119 & 232 & 7.8 & 5.9 & 90 & 32 \\
\hline 10 & 58 & 30.0 & 53 & 28 & 40 & 96 & 136 & 7.9 & 5.7 & 91 & 37 \\
\hline $\begin{array}{l}\text { Mean } \\
\text { (SD) }\end{array}$ & $\begin{array}{l}58 \\
(7)\end{array}$ & $\begin{array}{l}30.5 \\
(4.9)\end{array}$ & $\begin{array}{l}56 \\
(8)\end{array}$ & $\begin{array}{c}36 \\
(10)\end{array}$ & $\begin{array}{c}47 \\
(10)\end{array}$ & $\begin{array}{l}103 \\
(15)\end{array}$ & $\begin{array}{l}197 \\
(54)\end{array}$ & $\begin{array}{c}8.1 \\
(0.4)\end{array}$ & $\begin{array}{c}5.6 \\
(0.6)\end{array}$ & $\begin{array}{l}91 \\
(1)\end{array}$ & $\begin{array}{c}41 \\
(22)\end{array}$ \\
\hline
\end{tabular}

*: FEV1\%: FEV1/FVC $\times 100$. Subj: subject; BMI: body mass index; FVC: forced vital capacity; FEV1: forced expiratory volume in one second; TLC: total lung capacity; RV: residual volume; \% pred: percentage of predicted value [16, 17]; $P$ a, $\mathrm{O}_{2}:$ arterial oxygen tension; $\mathrm{Pa}_{\mathrm{a}} \mathrm{CO}_{2}$ : arterial carbon dioxide tension; $\mathrm{Sa}_{\mathrm{a}} \mathrm{O}_{2}$ : arterial oxygen saturation; AHI: apnoea-hypopnoea index. 
nCPAP and was thereafter increased progressively in a similar way to that of the previous night.

Arterial blood gas measurements. Arterial blood gas measurements were performed during the second and third nights prior to the start of polysomnography, with the patient breathing room air whilst awake and supine. Multiple blood gases were later obtained during sleep at the end of apnoeas or hypopnoeas with $3 \mathrm{cmH}_{2} \mathrm{O}$ nCPAP and at random intervals with the maximum nCPAP level reached. All arterial blood samples and $\mathrm{pH}$ values were immediately analysed with a model IL-1312 blood gas analyser (Instrumentation Laboratories, Lexington, MA, USA).

Lung function was assessed using a Pulmonary Calculator System HP 47804A (Hewlett-Packard, Palo Alto, CA, USA) and a constant volume Jaeger plethysmograph (Würzburg, Germany).

\section{Data analysis}

Sleep stage was scored by standard criteria [19]. An obstructive apnoea was defined as absence of airflow at the nose and mouth for $\geq 10 \mathrm{~s}$ with continued respiratory effort. Hypopnoea was defined as a decrease in the Respitrace sum signal of $\geq 50 \%$ for $\geq 10$ s when compared to the peak amplitude lasting for $\geq 10 \mathrm{~s}$ that occurred within the previous $2 \mathrm{~min}$ in the presence of continued airflow [20]. The apnoea plus hypopnoea index (AHI) was defined as the number of apnoeas and hypopnoeas per hour of sleep. Mean $\mathrm{Sa}, \mathrm{O}_{2}$ during sleep was determined by averaging the saturation tracings every $10 \mathrm{~s}$ and a desaturation event was defined as a reduction in $\mathrm{Sa}_{\mathrm{a}} \mathrm{O}_{2}$, by at least $4 \%$ for a duration of $\geq 10 \mathrm{~s}$.

Given the variability of upper airway closing pressure in the different sleep phases [21], comparisons of AHI at each nCPAP level were made during periods of the same phase of nREM sleep (I-II or III-IV) with a minimum duration of $15 \mathrm{~min}$. Comparisons were usually made in phases I-II, in which patients remained for the major part of the sleep, until effective nCPAP was reached and the appearance of phases III-IV was observed. With the aim of not underassessing possible deterioration in the acid base balance induced by oxygen administration, only maximum arterial carbon dioxide tension $\left(\mathrm{Pa}, \mathrm{CO}_{2}\right)$ and minimum $\mathrm{pH}$ values were considered for analysis.

Data are expressed in the text and tables as mean (standard deviation). All statistical comparisons between data collected during the three nights were made by Friedman and Wilcoxon nonparametric tests, with significance adjusted by the Bonferroni method when simultaneous multiple comparisons between the three nights were performed. Significance was assigned at a p-value less than 0.05 or, when Bonferroni-corrected, at a p-value less than $0.0166(0.05 / 3=0.0166)$.

\section{Results}

No significant quantitative or qualitative differences in sleep were found between the three nights except for a greater duration of slow wave and REM sleep in the second and third nights, usually when effective nCPAP was reached (table 2). Three patients (Nos. 2, 4 and 7) presented no apnoeas during sleep; however, all of them presented frequent hypopnoeas during recording. The number of desaturations $\cdot \mathrm{h}^{-1}$ was 50 (24) with a mean nadir of 81 (4)\% in nREM sleep and 73 (9)\% in REM sleep, and a mean minimum value of 69 (9)\% and 61 (15)\% in NREM and REM sleep, respectively. Mean $\mathrm{Sa}_{\mathrm{a}} \mathrm{O}_{2}$ determined by pulse oximetry fell from a basal awake supine value of 90 (2)\% to 86 (2)\% during nREM sleep and 80 (7)\% during REM sleep ( $\mathrm{p}<0.03)$.

The maximum level of nCPAP applied during the second night was 9.5 (2.0) $\mathrm{cmH}_{2} \mathrm{O}$; at this level, AHI was 2.9 (3.7), and mean $\mathrm{Sa}_{\mathrm{a}} \mathrm{O}_{2}$ during nREM sleep 88 (2)\% with a mean minimum value of $83(4) \%$. Six patients

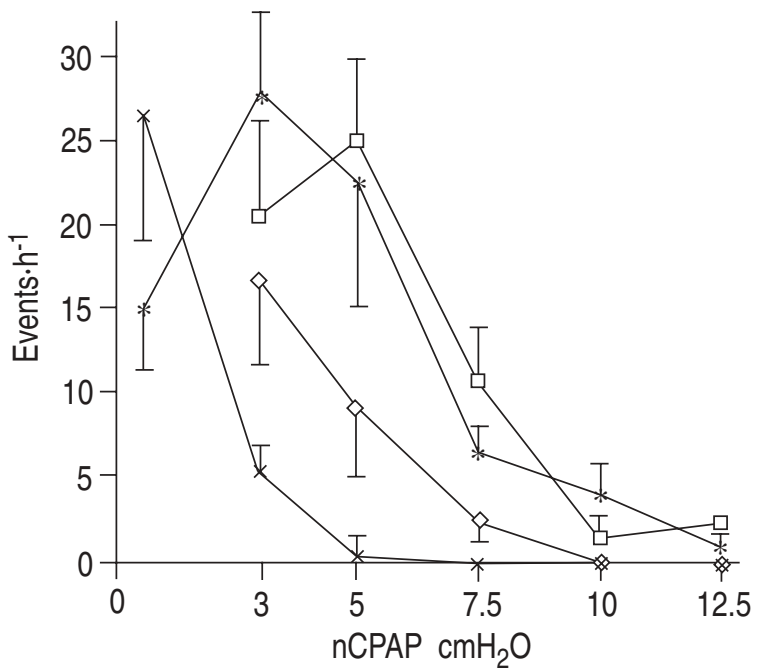

Fig. 1. - Apnoea and hypopnoea frequencies with increasing nCPAP levels with and without supplemental oxygen. Values at 0 nCPAP level are those obtained during the first night. Results are expressed as mean \pm SEM. $\rightarrow$ : apnoeas without $\mathrm{O}_{2} ; \multimap \neg$ : apnoeas with $\mathrm{O}_{2}$; * : hypopnoeas without $\mathrm{O}_{2} ; \multimap-:$ hypopnoeas with $\mathrm{O}_{2}$. nCPAP: nasal continuous positive airway pressure.

Table 2. - Sleep quality data

\begin{tabular}{lclclll}
\hline & \multicolumn{2}{c}{ Night 1} & \multicolumn{2}{c}{ Night 2} & \multicolumn{2}{c}{ Night 3 } \\
\hline Total sleep time min & 360 & $(44)$ & 362 & $(53)$ & 307 & $(76)$ \\
Sleep efficiency \% & 80 & $(10)$ & 73 & $(11)$ & 78 & $(9)$ \\
Slow-wave sleep min & 12.6 & $(7.2)$ & 37.7 & $(19.2)^{*}$ & $42.8(17.4)^{*}$ \\
REM sleep min & 28.4 & $(22.4)$ & 58.2 & $(36.3)^{*}$ & $44.0(33.2)^{*}$ \\
\hline
\end{tabular}

Values are presented as mean \pm SD in parentheses. REM: rapid eye movement. *: significant differences are in comparison with night $1(\mathrm{p}<0.01)$. 
Table 3. - Values of $\mathrm{Sa}, \mathrm{O}_{2}, \mathrm{~Pa}, \mathrm{O}_{2}, \mathrm{~Pa}_{\mathrm{a}} \mathrm{CO}_{2}$ and $\mathrm{pH}$ during nREM sleep on application of nasal continuous positive airway pressure (nCPAP) with and without supplemental oxygen

\begin{tabular}{|c|c|c|c|c|c|}
\hline \multirow{2}{*}{$\begin{array}{l} \\
\mathbf{n C P A P} \mathbf{3} \mathbf{c m H}_{2} \\
\mathrm{~S}_{\mathrm{a}, \mathrm{O}_{2}} * \%\end{array}$} & \multicolumn{2}{|c|}{ Without $\mathrm{O}_{2}$} & \multicolumn{2}{|c|}{ With $\mathrm{O}_{2}$} & p-value \\
\hline & & & & & \\
\hline Mean & 86 & (2) & 93 & (3) & $<0.01$ \\
\hline Minimum & 75 & (5) & 86 & (7) & $<0.01$ \\
\hline Mean nadir & 83 & (3) & 90 & (3) & $<0.01$ \\
\hline${\mathrm{Pa}, \mathrm{O}_{2}}^{+} \quad \mathrm{kPa}$ & 7.0 & $(0.40)$ & 8.5 & $(0.40)$ & $<0.01$ \\
\hline $\mathrm{mmH}$ & 52.6 & (3.0) & 64.1 & (3.0) & \\
\hline${\mathrm{Pa}, \mathrm{CO}_{2}}^{\dagger} \mathrm{kPa}$ & 6.8 & $(0.52)$ & 7.1 & $(0.83)$ & $<0.03$ \\
\hline $\mathrm{mm}$ & 51.2 & (3. & 52.9 & (6.2) & \\
\hline $\mathrm{pH}^{*}$ & 7.35 & (0.03) & 7.34 & $(0.03)$ & NS \\
\hline Maximum ne & & & & & \\
\hline $\mathrm{Sa}, \mathrm{O}_{2} * \%$ & & & & & \\
\hline Mean & 88 & (2) & 93 & (2) & $<0.0$ \\
\hline Minimun & 83 & $(4$ & 89 & (3 & $<0.0$ \\
\hline$P \mathrm{a}, \mathrm{O}_{2}{ }^{+}$ & 7.3 & $(0.28)$ & 8.6 & $(0.37)$ & $<0.01$ \\
\hline $\mathrm{mmF}$ & 54.9 & (2.1) & 64.5 & (2.8) & \\
\hline${\mathrm{Pa}, \mathrm{CO}_{2}^{\dagger}}^{\dagger} \mathrm{kPa}$ & 6.4 & $(0.55)$ & 6.5 & $(0.61)$ & NS \\
\hline $\mathrm{mmHg}$ & 48.1 & (4.1) & 48.8 & (4.6) & \\
\hline $\mathrm{I}^{\#}$ & 7.37 & $(0.02)$ & 7.36 & $(0.02)$ & NS \\
\hline
\end{tabular}

Values are presented as mean, and SD in parenthesis. *: from saturation tracings; ${ }^{+}$: mean value from arterial blood gas measurements; ${ }^{\dagger}$ : maximum value from arterial blood gas measurements; \#: minimum value from arterial blood gas measurements. Arterial blood gas measurements were obtained at the end of apnoeas or hypopnoeas with $3 \mathrm{cmH}_{2} \mathrm{O}$ nCPAP and at random intervals with the maximum nCPAP reached. NS: nonsignificant. For further abbreviations see legend to table 1 .

Table 4. - Apnoea (Al) and hypopnoea (HI) frequency (events. $\mathrm{h}^{-1}$ ) and duration during NREM sleep in the second and third nights with nCPAP $3 \mathrm{cmH}_{2} \mathrm{O}$

\begin{tabular}{lrrrrrc}
\hline & \multicolumn{2}{c}{ Without $\mathrm{O}_{2}$} & \multicolumn{2}{c}{ With $\mathrm{O}_{2}$} & p-value \\
\hline AI & 5.2 & $(6.7)$ & 16.6 & $(21.1)$ & $<0.03$ \\
HI & 27.7 & $(17.4)$ & 20.4 & $(14.8)$ & NS \\
AHI & 32.9 & $(22.1)$ & 37.0 & $(22.2)$ & NS \\
Mean duration & s & 12.9 & $(2.0)$ & 16.8 & $(4.4)$ & $<0.02$ \\
\hline
\end{tabular}

Values are presented as mean, and SD in parenthesis. AI: apnoea index; HI: hypopnoea index; AHI: apnoea-hypopnoea index; nCPAP: nasal continuous positive airway pressure; Ns: nonsignificant; NREM: non-rapid eye movement.

achieved REM sleep with the maximum nCPAP applied, and presented a mean $\mathrm{Sa}_{\mathrm{a}} \mathrm{O}_{2}$ of 85 (4)\% and a mean minimum value of $79(6) \%$. Characteristically, the decrease in the number of obstructive apnoeas was achieved with lower pressures than those required in hypopnoeas (fig. 1) and, when low levels of nCPAP were applied, apnoea frequency decreased accompanied by an increase in hypopnoeas.

The application of oxygen associated with nCPAP during the third night improved oxygenation during sleep without producing a clinically significant increase in $P \mathrm{a}, \mathrm{CO}_{2}$ or induction of cardiac arrhythmias. This improvement was observed at low nCPAP levels despite the persistence of apnoeas and hypopnoeas (table 3 ). All patients presented a mean $\mathrm{S}_{\mathrm{a}} \mathrm{O}_{2}$ above $91 \%$ in nREM phase during the third night with the maximum nCPAP applied. This value was not reached by any patient during the second night. In the seven patients who achieved REM sleep with maximum nCPAP, mean $\mathrm{Sa}_{\mathrm{a}} \mathrm{O}_{2}$ was 91 (2)\%, less than that corresponding to nREM sleep, 92 (2)\% $(\mathrm{p}<0.05)$. The minimum $\mathrm{Sa}, \mathrm{O}_{2}$ detected at any time in the REM phase was similarly lower, 87 (4)\% vs 88 (3)\% in REM and NREM sleep, respectively $(\mathrm{p}<0.05)$.

The application of nCPAP with supplemental oxygen produced a progressive decrease in apnoeas and hypopnoeas; however, this decrease differed from that observed with the application of nCPAP without associated oxygen. At low nCPAP levels an increase in apnoea index and apnoea-hypopnoea duration (table 4) were detected. Furthermore, the apnoeas persisted with nCPAP levels that eliminated them when applied without supplemental oxygen (fig. 1). With the exception of one patient (No. 5), who did not tolerate the level achieved during the second night, the progressive increase in nCPAP eliminated first apnoeas and then hypopnoeas as occurred during the second night, with the effectiveness of the maximum level reached during the second night being maintained. Seven patients (Nos. 2, 3, 4, 7, 8, 9 and 10) achieved REM sleep without obstructive apnoeas at the maximum level of nCPAP as occurred in nREM sleep at the same pressure, and a mean hypopnoea frequency, 4.3 (2.7) events $\cdot \mathrm{h}^{-1}$ and duration, $17.6(10.3) \mathrm{s}$ similar to those of the nREM phase, 2.6 (3.6) and 13.3 (2.8), respectively (NS).

\section{Discussion}

In our patients, the coexistence of COPD and SAHS determined poor nocturnal oxygenation that was only partially corrected by the application of nCPAP. The mean value of $\mathrm{Sa}_{\mathrm{a}} \mathrm{O}_{2}$ remained below $90 \%$ in all patients, despite correction of apnoeas and hypopnoeas. Improved $\mathrm{Sa}, \mathrm{O}_{2}$ values during sleep were obtained by the addition of low flow supplemental oxygen to the nCPAP circuit.

Correction of nocturnal hypoxaemia in these patients by the application of oxygen alone is not an ideal therapeutic alternative. GoLDSTEIN et al. [22] administered oxygen by nasal prongs at a flow rate of $1-2 \mathrm{~L} \cdot \mathrm{min}^{-1}$ to a group of 12 patients with severe COPD and observed marked hypercapnia during sleep and morning cephaleas in three patients who presented associated SAHS. These authors did not describe the effect of oxygen therapy on episodes of upper airway obstruction or on heart rate. Alford et al. [23] administered oxygen at $4 \mathrm{~L} \cdot \mathrm{min}^{-1}$ to 20 subjects with COPD and SAHS, detecting frank improvements in mean $\mathrm{Sa}_{\mathrm{a}} \mathrm{O}_{2}$ during sleep and apnoeaassociated bradycardia. However, they did observe the persistence of frequent upper airway obstructive episodes, which have been shown to lead to persistent cardiopulmonary haemodynamic alterations and, frequently, SAHS symptoms [5]. In addition, they detected decreased $\mathrm{pH}$ and increased $P \mathrm{a}, \mathrm{CO}_{2}$ during oxygen administration, which they attributed to the greater duration of apnoea episodes 
observed and the induction of greater hypoventilation during sleep.

During the third night, we did not observe greater hypercapnia or higher frequency of cardiac arrhythmias than those observed with nCPAP without associated oxygen. Only two of the patients studied were hypercapnic (daytime $\mathrm{Pa}, \mathrm{CO}_{2}>6.0 \mathrm{kPa}(>45) \mathrm{mmHg}$ ), a condition associated with blunted $\mathrm{CO}_{2}$ responsiveness that may imply an increased role of hypoxia as a stimulus involved in apnoea termination and ventilation maintenance. When maximum nCPAP with supplemental oxygen was applied in these two cases, we detected maximum increases in $\mathrm{Pa}_{\mathrm{a}, \mathrm{CO}_{2}}(0.4$ and $0.9 \mathrm{kPa}(3$ and $7 \mathrm{mmHg})$ ) similar to those of nonhypercapnic patients, in contrast to the results of ALFORD et al. [23], who found a greater increase in $P \mathrm{a}, \mathrm{CO}_{2}$ associated with oxygen therapy in hypercapnic than in normocapnic patients $(3.02 v s 1.75 \mathrm{kPa}(22.7 v s$ $13.1 \mathrm{mmHg}$ ); $\mathrm{p}<0.001)$. However, their data corresponded to end-apnoeic arterial blood gases and retainer patients showed greater apnoea prolongation whilst on supplemental oxygen. In contrast, our $\mathrm{Pa}_{\mathrm{a}} \mathrm{CO}_{2}$ values were obtained following elimination of upper airway obstruction episodes and are similar to those reported in hypercapnic COPD patients without SAHS whilst on supplemental oxygen [22].

To determine the effect of the addition of oxygen to the nCPAP circuit, we adopted the best validated definition of hypopnoea, whose equivalence to episodes of partial upper airway obstruction and clinical importance in the development of the SAHS in the absence of apnoeas has been demonstrated [20]. Supplemental oxygen did not lead to a change in effective nCPAP pressure. However, with the application of increasing nCPAP levels, we detected differences in apnoea and hypopnoea frequencies with suboptimal pressures. The main finding was an increased frequency of apnoeas at low nCPAP levels and their persistence at pressures which abolished them during the night that oxygen was not added. A rebound effect from the second night was unlikely because we did not find sleep quality differences between these two nights, and comparisons of AHI at each nCPAP level were made during the same phase of nREM sleep. Internocturnal variability of AHI has been reported [24] and related in part to body position during sleep [25]. However, we consider it unlikely that systematic changes, such as those observed, may be attributed to this variability and, although posture during sleep was not strictly limited, we know from continuous visual monitoring that each patient was basically studied supine with a constant head and neck position. On the other hand, closing and reopening pressures of the upper airway show scarce intraindividual variability $[21,26]$. Thus, although treatment administered during the second and third nights was not randomized, we consider the changes observed to be secondary to the addition of oxygen to the nCPAP circuit.

In patients with obstructive apnoeas, Sмiтн et al. [27] observed minimal inspiratory flows when low nCPAP levels were applied, and KUNA et al. [28] reported a progressively increasing pharyngeal area when nCPAP levels were raised. We believe that when low nCPAP levels were applied supplemental oxygen induced the transition of some hypopnoeas to apnoeas. This transition may have been caused by the decrease in upper airway muscle activity normally present at the start of obstructive episodes [29]. Studies in animals [12, 13, 30, 31], normal humans [14], and SAHS patients [32] have shown that hypoxia and marked hypercapnia determine a preferential increase in upper airway muscle activity compared with that of the diaphragm, and an inverse effect of hyperoxia, hypocapnia and mild hypercapnia. Furthermore, in the range of $\mathrm{Sa}, \mathrm{O}_{2}$ values considered in our study, a strong linear relationship has been observed between $\mathrm{Sa}_{2} \mathrm{O}_{2}$ and upper airway muscle activity [33] and upper airway resistance [34] (inverse and positive relationships, respectively). In accordance with the above observations, our results showed an increase in apnoeic episodes in a clinical context when hypoxia was corrected with no significant increase in $\mathrm{Pa}_{\mathrm{a}} \mathrm{CO}_{2}$. The efficacy of higher levels of nCPAP would not be affected by upper airway muscle activity, since they would act only through passive pneumatic distension [33].

In summary, our results show the addition of oxygen to nCPAP to be a practical, effective therapy for hypoxic patients with coexistent SAHS and COPD, since it permits correction of both upper airway obstructive episodes and nocturnal hypoxaemia. In addition, we observed a higher frequency of apnoeic episodes at low nCPAP levels when oxygen was added. We speculate that this increase is observed only at levels below that of effective nCPAP without supplemental oxygen, which remains unaffected when oxygen is added. Further studies are required to elucidate this last point and establish whether control polysomnography with nCPAP and oxygen is necessary to determine the effective pressure in these patients.

Acknowledgement: The authors thank C. O'Hara for help with the English translation.

\section{References}

1. Bradley TD, Rutherford R, Grossman RF, et al. Role of daytime hypoxemia in the pathogenesis of right heart failure in the obstructive sleep apnea syndrome. Am Rev Respir Dis 1985; 131: 835-839.

2. Bradley TD, Martinez D, Rutherford R, et al. Physiological determinants of nocturnal arterial oxygenation in patients with obstructive sleep apnea. J Appl Physiol 1985; 59: 1364-1368.

3. Weitzenblum E, Krieger J, Apprill M, et al. Daytime pulmonary hypertension in patients with obstructive sleep apnea syndrome. Am Rev Respir Dis 1988; 138: 345-349.

4. Douglas NJ. Breathing during sleep in patients with respiratory disease. In: Guilleminault C, Partinen M, eds. Obstructive Sleep Apnea Syndrome: Clinical Research and Treatment. New York; Raven Press Ltd, 1990: pp. 37-48.

5. Fletcher EC, Schaaf JW, Miller J, Fletcher JG. Longterm cardiopulmonary sequelae in patients with sleep apnea and chronic lung disease. Am Rev Respir Dis 1987; 135: 525-533. 
6. Fletcher EC, Brown DL. Nocturnal oxyhemoglobin desaturation following tracheostomy for obstructive sleep apnea. Am J Med 1985; 79: 35-42.

7. Nocturnal Oxygen Therapy Trial Group. Continuous or nocturnal oxygen therapy in hypoxemic chronic obstructive lung disease: a clinical trial. Ann Intern Med 1980; 93: 391-398.

8. Medical Research Council Working Party Report. Long term domiciliary oxygen therapy in chronic hypoxic cor pulmonale complicating chronic bronchitis and emphysema. Lancet 1981; i: 681-686.

9. Remmers JE, de Groot WJ, Sauerland EK, Anch AM. Pathogenesis of upper airway occlusion during sleep. $J$ Appl Physiol: Respirat Environ Exercise Physiol 1978; 44: 931-938.

10. Brouillette RT, Thach BT. A neuromuscular mechanism maintaining extrathoracic airway patency. $J$ Appl Physiol: Respirat Environ Exercise Physiol 1979; 46: 772 779.

11. Block AJ, Faulkner JA, Hughes RL, Remmers JE, Thach B. Factors influencing upper airway closure. Chest 1984; 86: 114-122.

12. Brouillette RT, Thach BT. Control of genioglossus muscle inspiratory activity. J Appl Physiol: Respirat Environ Exercise Physiol 1980; 49: 801-808.

13. Weiner D, Mitra J, Salamone J, Cherniack NS. Effect of chemical stimuli on nerves supplying upper airway muscles. J Appl Physiol: Respirat Environ Exercise Physiol 1982; 52: 530-536.

14. Hudgel DW, Chapman KR, Faulks C, Hendricks C. Changes in inspiratory muscle electrical activity and upper airway resistance during periodic breathing induced by hypoxia during sleep. Am Rev Respir Dis 1987; 135: 899-906.

15. American Thoracic Society. Standards for the diagnosis and care of patients with chronic obstructive pulmonary disease (COPD) and asthma. Am Rev Respir Dis 1987; 136: 225-244.

16. Roca J, Sanchis J, Agusti-Vidal A, et al. Spirometric reference values from a Mediterranean population. Bull Eur Physiopathol Respir 1986; 22: 217-224.

17. Roca J, Segarra F, Rodriguez-Roisin R, Cobo E, Martinez J, Agustí-Vidal A. Static lung volumes and single-breath diffusing capacity: reference values from a Latin population. Am Rev Respir Dis 1985; 131 (Suppl.): A352.

18. Chadha TS, Watson H, Birch S, et al. Validation of respiratory inductive plethysmography using different calibration procedures. Am Rev Respir Dis 1982; 125: 644-649.

19. Rechtschaffen A, Kales A (eds). In: A manual of standardized terminology, techniques and scoring system for sleep stages of human subjects. Bethesda, MD, NIH publication No. 204, 1968.

20. Gould GA, Whyte KF, Rhind GB, et al. The sleep hypopnea syndrome. Am Rev Respir Dis 1988; 137: 895-898.

21. Issa FG, Sullivan CE. Upper airway closing pressures in obstructive sleep apnea. J Appl Physiol: Respirat Environ Exercise Physiol 1984; 57: 520-527.

22. Goldstein RS, Ramcharan V, Bowes G, McNicholas WT, Bradley D, Phillipson EA. Effect of supplemental oxygen on gas exchange in patients with severe obstructive lung disease. $N$ Engl J Med 1984; 310: 425-429.

23. Alford NJ, Fletcher EC, Nickeson D. Acute oxygen in patients with sleep apnea and COPD. Chest 1986; 89: 30-38.

24. Guilleminault C, van den Hoed J, Mitler MM. Clinical overview of the sleep apnea syndromes. In: Guilleminault C, Dement WC, eds. Sleep Apnea Syndromes. New York, Alan R. Liss, 1978: pp. 2-12.

25. Cartwright RD. Effect of sleep position on sleep apnea severity. Sleep 1984; 7: 110-114.

26. Olson LG, Strohl KP. Nonmuscular factors in upper airway patency in the rabbit. Respir Physiol 1988; 71: 147-155.

27. Smith PL, Wise RA, Gold AR, Schwartz AR, Permutt S. Upper airway pressure-flow relationships in obstructive sleep apnea. J Appl Physiol 1988; 64: 789-795.

28. Kuna ST, Bedi DG, Ryckman C. Effect of nasal airway positive pressure on upper airway size and configuration. Am Rev Respir Dis 1988; 138: 969-975.

29. Suratt PM, Mctier RF, Wilhoit SC. Upper airway muscle activation is augmented in patients with obstructive sleep apnea compared with that in normal subjects. Am Rev Respir Dis 1988; 137: 889-894.

30. Bruce EN, Mitra J, Cherniack NS. Central and peripheral chemoreceptor inputs to phrenic and hypoglossal motoneurons. J Appl Physiol: Respirat Environ Exercise Physiol 1982; 53: 1504-1511.

31. Parisi RA, Neubauer JA, Frank MM, Edelman NH, Santiago TV. Correlation between genioglossal and diaphragmatic responses to hypercapnia during sleep. Am Rev Respir Dis 1987; 135: 378-382.

32. Hudgel DW, Hendricks C, Dadley A. Alteration in obstructive apnea pattern induced by changes in oxygen and carbon dioxide inspired concentrations. Am Rev Respir Dis 1988; 138: 16-19.

33. Strohl KP, Redline S. Nasal CPAP therapy, upper airway muscle activation, and obstructive sleep apnea. Am Rev Respir Dis 1986; 134: 555-558.

34. Dinh L, Maltais F, Sériès F. Influence of progressive and of transient hypoxia on upper airway resistance in normal humans. Am Rev Respir Dis 1991; 143: 1312-1316. 